\title{
TENS for pain relief-the power of suggestion
}

Richard D. Wigley

I read with interest the News \& Views article by Johnson and Walsh published in Nature Reviews Rheumatology (Continued uncertainty of TENS' effectiveness for pain relief. Nat. Rev. Rheumatol. 6, 314-316 [2010]). ${ }^{1}$ The authors of this article seemingly use the term 'effectiveness' to imply that TENS is not more effective than placebo. Dubinsky and Myasaki state that TENS is ineffective in treating back pain, when they really mean that it is not more effective than placebo. ${ }^{2}$ This is confusing as there is much evidence that TENS is effective as a placebo (sham TENS). The crucial unanswered question is whether there is an effect specific to TENS in addition to the effect of the placebo. ${ }^{3}$

With TENS the electrical stimulus is felt by the subject and so carries a strong suggestion that it will be effective, as placebo. Sham TENS procedures also carry a positive suggestion. Some years ago in a study of hand pain in rheumatoid arthritis my colleagues and I "raised the dose of suggestion" (placebo) by displaying the electrical current on a video screen. ${ }^{4}$ In otherwise blind conditions, we obtained equal pain relief whether the patient received the electrical current or not. We concluded that that a strong visual suggestion was as potent as the suggestion from the electrical sensation from the TENS machine, which was therefore just a less potent placebo than the visual stimulus.

I would suggest that this method be applied in other types of pain. A positive result would then answer the questions raised by Drs Johnson and Walsh. They describe a mechanism by which TENS may work but this might actually be the mechanism by which placebo works.

I do not wish to imply that TENS should not be used. Suggestion that recovery will occur is a very desirable ingredient in any treatment or rehabilitation whether it is applied by verbally, electrically or by smell, touch or through any of our senses. Physiotherapists use similar machines that cannot be blinded for standard randomized, double-blind, controlled trials, but all agree that they do assist their patients to recover. The power of suggestion should not be under estimated: the whole advertising industry, and so newspapers and magazines and television, depend on it.

240 Park Road, Palmerston North 4410,

New Zealand.

r.d.wigley@xtra.co.nz

doi:10.1038/nrrheum.2010.77-c1

Competing interests

The author declares no competing interests.

1. Johnson, M. I. \& Walsh, D. M. Continued uncertainty of TENS' effectiveness for pain relief. Nat. Rev. Rheumatol. 6, 314-316 (2010).

2. Dubinsky, R. M. \& Miyasaki, J. Assessment: efficacy of transcutaneous electric nerve stimulation in the treatment of pain in neurologic disorders (an evidence-based review): report of the Therapeutics and Technology Assessment Subcommittee of the American Academy of Neurology. Neurology 74, 173-176 (2010).

3. Wigley, R. When is a placebo effect not an effect? Clin. Med. 7, 450-452 (2007).

4. Langley, G. B., Sheppard, H., Johnson, M. \& Wigley, R. D. The analgesic effect of transcutaneous electrical nerve stimulation and placebo in chronic pain patients. A double-blind non-crossover comparison. Rheumatol. Int. 4, 119-123 (1984). 